\title{
O QUE É PRODUZIDO NA FOTOSSÍNTESE? - ANÁLISE DESSE PROCESSO A PARTIR DE LIVROS DIDÁTICOS DO ENSINO FUNDAMENTAL E MÉDIO
}

\author{
PIRES, Bárbara Balzana Mendes ${ }^{1}$ - UERJ \\ ALMEIDA, Lidiane Aparecida ${ }^{2}$ - UERJ \\ PORTO, Maria Beatriz Dias da Silva Maia ${ }^{3}$ - UERJ
}

\begin{abstract}
RESUMO:
Os livros didáticos são, muitas vezes, utilizados pelos professores sem que seja realizada uma análise cuidadosa acerca dos conceitos abordados por seus autores. Apesar de todo o cuidado que se deveria ter ao editar um livro didático, muitas vezes alguns desses conceitos ficam desatualizados com o passar dos anos ou, ainda, são mal interpretados a partir de sua pesquisa de origem. Este é um problema comum a livros didáticos de diversas disciplinas. Deteremo-nos, aqui, na análise realizada em alguns livros da Educação Básica e da Educação Superior, da área de Biologia, nos quais detectamos que o processo da fotossíntese não é apresentado de forma clara. Nestas obras, de uma forma geral, a fotossíntese aparece como o processo que usa a energia luminosa para converter o dióxido de carbono e a água em açúcares. No entanto, em muitos livros, a glicose aparece como o açúcar produzido neste processo, seja através da representação de sua fórmula química na equação geral da fotossíntese, ou em esquemas didáticos do processo como um todo, seja como produto final na conceituação deste processo. Assim, foi proposta uma nova abordagem desse conceito para livros didáticos, considerando uma das primeiras equações gerais da fotossíntese elucidadas por Calvin.
\end{abstract}

Palavras-chave: Fotossíntese - Conceitos de Biologia - Glicose - Livros didáticos.

\footnotetext{
ABSTRACT:

Didactical books are frequently used by teachers without a critical analysis over the concepts employed by their authors. Despite all the care it should be taken in editing a didactical book, many times some of these concepts either become out of date as years wear on or are subject to misinterpretations of primary sources. This is a common problem shared by didactical works

${ }^{1}$ Doutora em Biologia: Biotecnologia Vegetal pela UFRJ. Professora Adjunta da Universidade do Estado do Rio de Janeiro (UERJ). E-mail: barbarabalzana@gmail.com.

${ }^{2}$ Doutora em Química: Ciências, Ciência e Tecnologia de Polímeros. Professora Adjunta da Universidade do Estado do Rio de Janeiro (UERJ). E-mail: lidiane_li@ig.com.br

${ }^{3}$ Doutora em Física: Teoria Quântica de Campos pela UFRJ. Professora Adjunta da Universidade do Estado do Rio de Janeiro (UERJ). E-mail: beatrizrj@mail.com.
} 
of various disciplines. We will focus on the analysis performed in some Biology books of Basic and Superior educational levels, where we have detected, among other problems, that the photosynthesis's process is presented in an unclear way. Generally speaking, in these works photosynthesis appears as the process that uses luminous energy to convert water and carbon dioxide into sugar. Nevertheless, in many books glucose appears as the sugar produced by this process, either by the representation of its chemical formula in the general photosynthesis equation or within didactical schemes of the process as a final product, or in its conceptualization. Therefore, in this work we propose a new approach of this concept destinated to didactical books, based on the first general equation of photosynthesis defined by Calvin.

KEY WORDS: Photosyntesis - Biology concepts - Glucose - Didactic books.

\section{INTRODUÇÃO}

Os cursos de formação inicial e continuada de professores da área de ciências naturais no Brasil têm revelado que os professores apresentam dificuldades no ensino de determinados conteúdos. Atribuímos essas dificuldades a fatores como falhas em suas formações básicas de graduação, sobretudo em seu ciclo básico, dificuldades em realizar a transposição didática para a Educação Básica de conteúdos que têm mais profundidade, a utilização de livros didáticos sem qualquer crítica por parte do professor e, finalmente, o caso que analisaremos aqui: a presença de erros conceituais nesses livros didáticos.

Muitas vezes, o livro didático se resume à única fonte de consulta do professor. Desta forma, ao desenvolver suas atividades, de forma acrítica, utilizando livros que abordem conteúdos de forma errada, pouco rigorosa ou superficial, o professor acabará por transmitir os conteúdos de forma errada ou equivocada. $E$, o mais grave desta situação é o fato de que algumas concepções alternativas dos estudantes e dos professores poderão ser reforçadas, comprometendo o processo ensino-aprendizagem de forma significativa.

Diante do exposto, a análise de livros e materiais didáticos vem sendo objeto de pesquisas por parte de estudiosos da área de Educação e, em alguns cursos de formação de professores, já existe, na grade curricular, a disciplina "Análise de Livros e de Material Didático para Professores da Educação Básica". Este é o caso de alguns cursos de licenciatura oferecidos pela Universidade do Estado do Rio de Janeiro.

O Programa Nacional do Livro Didático (PNLD), que subsidia o trabalho realizado nas escolas públicas através da distribuição de livros aos estudantes dessas escolas, fez com que as editoras se tornassem mais exigentes com relação à revisão das obras por elas editadas. No entanto, ainda existem muitas melhorias a serem realizadas nessas edições.

Neste artigo, será apresentado o estudo de caso do conceito e equação da fotossíntese, a partir da avaliação de vinte livros didáticos, sendo dez do ensino fundamental, oito do ensino médio e dois da Educação Superior, nas áreas de Fisiologia Vegetal e introdução à Botânica. A partir dessa análise, pode-se perceber que, de uma maneira geral, os livros abordam a fotossíntese como o processo que usa a energia luminosa para converter o dióxido de carbono e a água em açúcares. 
O processo de fotossíntese ocorre desde que surgiu o primeiro ser autótrofo, porém, as reações deste processo foram elucidadas com a contribuição de muitos cientistas há algumas centenas de anos. As publicações que abordam esse tema, normalmente, representam a equação química geral equilibrada da fotossíntese como:

$$
6 \mathrm{CO}_{2}+6 \mathrm{H}_{2} \mathrm{O} \rightarrow \mathrm{C}_{6} \mathrm{H}_{12} \mathrm{O}_{6}+6 \mathrm{O}_{2} \text {. }
$$

A explicação para a equação é descrita, de forma geral, como o processo que usa a energia luminosa para converter o gás carbônico e a água em açúcares. A maioria das publicações se refere à glicose como o açúcar produzido nesse processo. Porém, durante o processo de fixação do carbono, é produzido um aldeído de três carbonos, e a glicose é apenas percussora na formação dos glicídios mais comuns nas plantas, a sacarose e o amido.

\section{Objetivos}

O presente trabalho propõe uma nova representação para a reação da fotossíntese e uma definição mais correta, no ponto de vista químico, da molécula orgânica produzida neste processo, para os livros de ensino fundamental e médio.

\section{Metodologia}

Para uma discussão a respeito deste tema, foram analisados vinte livros, sendo dez utilizados no ensino fundamental, oito no ensino médio e dois na graduação em biologia. Todos os livros de ensino médio e fundamental utilizados são volumes 1 e 2, respectivamente, de uma coleção completa para o segmento, pois é nesses volumes que o tema Fotossíntese é tratado, de acordo com o currículo de Ciências e Biologia. Não foram analisados livros de volume único para os segmentos médio e fundamental e todos faziam parte de uma coleção proposta pela editora para o Programa Nacional do Livro Didático PNLD. Os livros de graduação selecionados têm como tema a introdução à botânica e à fisiologia vegetal.

$\mathrm{Na}$ redação dos livros de ensino fundamental será avaliada principalmente a descrição geral do processo de fotossíntese e se menciona a da molécula produzida, além de outras observações, se houverem.

Já nos livros de ensino médio e graduação, foram analisados critérios quanto a estarem corretos, errados ou incompletos no uso da informação e outras observações relevantes. Os critérios utilizados na análise dos livros de ensino médio e graduação foram quanto:

i- à definição básica do processo de fotossíntese;

ii- à equação química geral apresentada,

iii-ao tipo de molécula orgânica que é definida como o produto final do processo.

\section{RESULTADOS E DISCUSSÃo}

Análise dos livros de ensino fundamental quanto à descrição geral do processo

$\mathrm{Na}$ maioria dos livros de ensino fundamental, a fotossíntese é descrita como o processo em que os vegetais absorvem água e gás carbônico do ambiente e transformam estes em glicose, utilizando a energia do Sol, e obtendo gás oxigênio (CANTO, 2009; SANTANA et al., 2009; PEREIRA et al., 2009; FAVALLI et al., 2010; GEWANDSZNAJDER et al., 2010; BARROS et al., 2010; SANGARI, 2007). Os autores Santana e Fonseca (SANTANA et al., 2009) inclusive apresentam uma figura, na qual a glicose é representada como produto da fotossíntese (Fig. 1a). Já Gewandsznajder 
(GEWANDSZNAJDER et al., 2010) mostra o produto como sendo apenas açúcar (Fig. 1b).

Figueiredo (FIGUEIREDO et al., 2009) menciona que o açúcar glicose, produzido nas folhas, passa por tubos que circulam por toda a planta para sua nutrição. Pereira (PEREIRA et al. 2009) e Bizzo (BIZZO, et al., 2009) se referem ao produto da fotossíntese como nutrientes, chamados açúcares. Alvarenga e colaboradores (ALVARENGA et al., 2008) mencionam o processo de fotossíntese de uma maneira muito geral, dizendo que ocorre quando os alimentos são fabricados pelos seres fotossintetizantes. Desta maneira, podemos perceber que, para o ensino fundamental, os autores mencionam a glicose como o açúcar resultante da fotossíntese, ou apresentam o produto desta reação apenas como açúcar.

Análise dos livros de ensino médio quanto à descrição básica do processo

A fotossíntese é definida pelos autores do ensino médio como uma série de etapas e processos complexos, onde carboidratos são produzidos a partir de água $\left(\mathrm{H}_{2} \mathrm{O}\right)$ e dióxido de carbono $\left(\mathrm{CO}_{2}\right)$ (SANTOS et al., 2010; MENDONÇA et al., 2010; PEZZI et al., 2010; LOPES et al., 2010; AMABIS et al., 2010; GEWANDSZNAJDER et al., 2010; BIZZO, 2011).
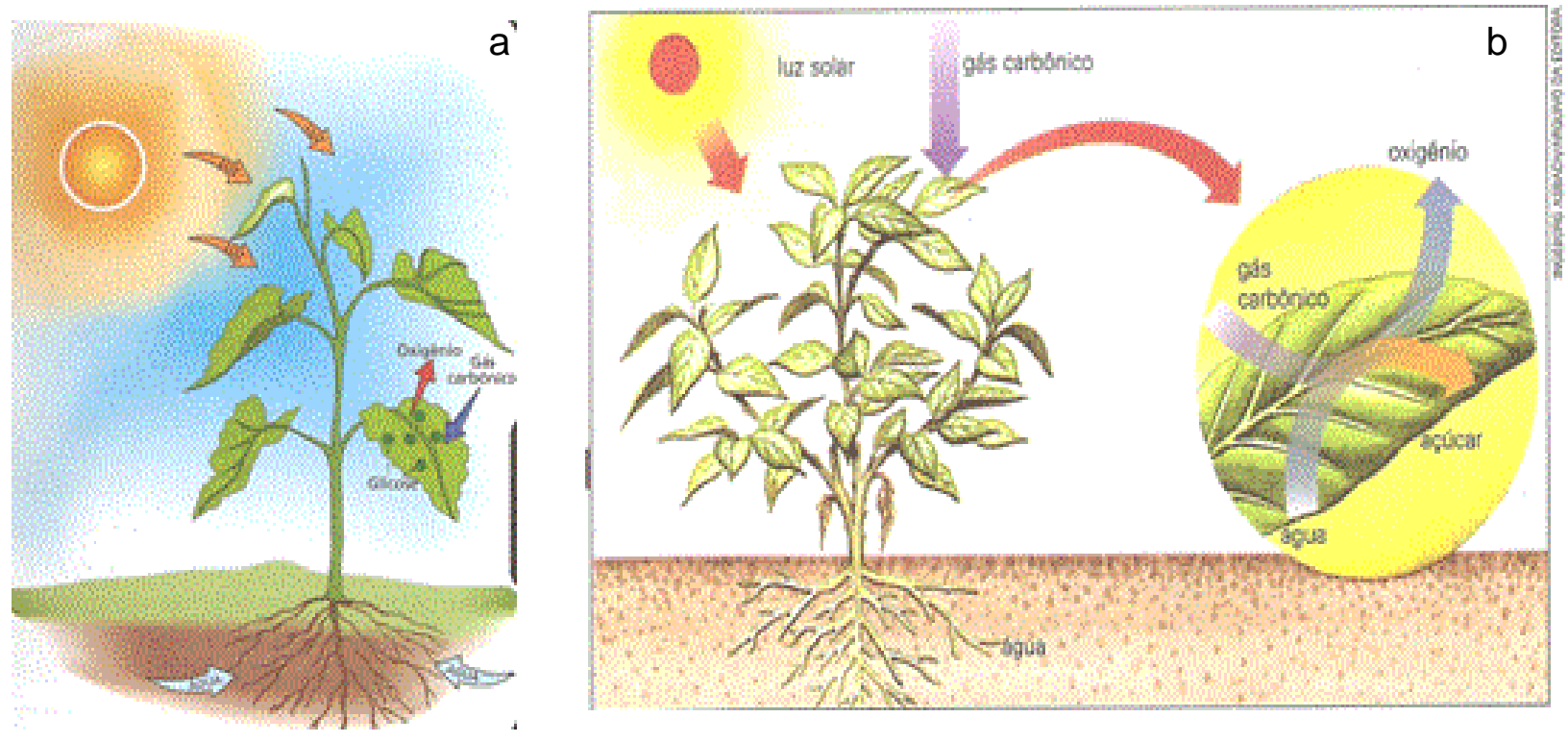

Figura 1 - Esquemas do processo de fotossíntese, indicando como produtos: (a) glicose e (b) açúcar. (SANTANA et al., 2009) e (GEWANDSZNAJDER et al., 2010), respectivamente. 
Amabis (AMABIS et al., 2010) ilustra a descrição geral de fotossíntese com uma figura que mostra a produção de glicose no processo de fotossíntese. No entanto, na legenda da figura, menciona-se que a glicose é normalmente representada como produto final da fotossíntese, mas muito pouca glicose livre é formada (Fig. 2).

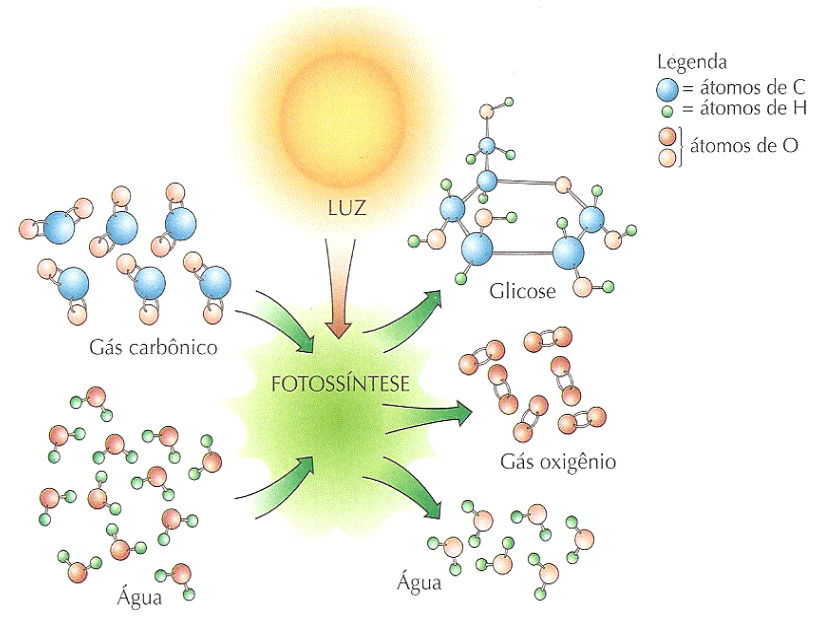

Figura 2 - Representação esquemática da fotossíntese, representando a glicose como produto final (AMABIS et al.,2010)

Equação química geral da fotossíntese apresentada nos livros de ensino médio

Santos e colaboradores (SANTOS et al., 2010) representam inicialmente a reação da fotossíntese, que descrevem como genérica pela reação 1 :

$2 \mathrm{H}_{2} \mathrm{O}+\mathrm{CO}_{2} \rightarrow \mathrm{CH}_{2} \mathrm{O}+\mathrm{H}_{2} \mathrm{O}+\mathrm{O}_{2}$ (Reação 1)
Os autores, (SANTOS et al., 2010), afirmam ainda que a glicose $\left(\mathrm{C}_{6} \mathrm{H}_{12} \mathrm{O}_{6}\right)$ é o carboidrato mais comumente representado e descrevem a reação da fotossíntese conforme a reação 2:

$12 \mathrm{H}_{2} \mathrm{O}+6 \mathrm{CO}_{2} \rightarrow \mathrm{C}_{6} \mathrm{H}_{12} \mathrm{O}_{6}+6 \mathrm{H}_{2} \mathrm{O}+6 \mathrm{O}_{2}$ (Reação 2)

Silva Júnior (SILVA JÚNIOR et al. 2010) apresenta as mesmas reações 1 e 2, mas elas são apresentadas de maneira inversa, mostrando a forma da equação simplificada (Reação 1) por último. Mendonça (MENDONÇA et al. 2010) faz a soma das equações das etapas da fotossíntese, também obtendo como resultado a Reação 2 . Silva Júnior (SILVA JÚNIOR et al. 2010) apresenta a reação 2 , e ainda adiciona a palavra glicose abaixo de $\mathrm{C}_{6} \mathrm{H}_{12} \mathrm{O}_{6}$ (Reação 3).

$$
\begin{gathered}
6 \mathrm{CO}_{2}+6 \mathrm{H}_{2} \mathrm{O}+\text { luz } \rightarrow 6 \mathrm{C}_{6} \mathrm{H}_{12} \mathrm{O}_{6}+6 \mathrm{O}_{2} \\
\text { (Reação 3) }
\end{gathered}
$$

(gás carbônico) (água) (glicose) (gás oxigênio)

Os autores (GEWANDSZNAJDER et al., 2010) resumem o processo da fotossíntese na reação 3 , porém ressaltam que o principal glicídio produzido não é a glicose. Diferentemente dos demais, os autores (LOPES et al., 2010) e (AMABIS et al., 2010) apresentam a equação da fotossíntese com uma triose, um carboidrato, sendo produzido, conforme a reação 4:

$$
\begin{aligned}
& 3 \mathrm{CO}_{2}+6 \mathrm{H}_{2} \mathrm{O} \rightarrow \mathrm{C}_{3} \mathrm{H}_{6} \mathrm{O}_{3}+3 \mathrm{O}_{2}+3 \mathrm{H}_{2} \mathrm{O} . \\
& \text { (Reação 4) }
\end{aligned}
$$


Porém, Lopes (Lopes et al., 2010) afirma que duas trioses unidas formam uma glicose e representa a equação da fotossíntese, de acordo com a reação 2 . Além disso, os referidos autores representam o carboidrato produzido pela sua fórmula geral, conforme a reação 1 .

Bizzo (BIZZO, 2011) se diferencia dos demais autores em relação à reação da fotossíntese, não vinculando a glicose como produto final, apresentando-a como na reação 5:

$$
\begin{gathered}
\mathrm{n} \mathrm{H}_{2} \mathrm{O}+\mathrm{n} \mathrm{CO}_{2} \rightarrow\left(\mathrm{CH}_{2} \mathrm{O}\right)_{\mathrm{n}}+\mathrm{O}_{2} \\
\text { (Reação 5) }
\end{gathered}
$$

A Reação 5 é muito semelhante à reação apresentada por Melvin Calvin, cientista que ganhou o prêmio Nobel de Química por elucidar as reações que formam os compostos produzidos a partir do dióxido de carbono e água, usando a energia da luz (CALVIN, 1961).

Definição pelos livros de ensino médio de qual molécula orgânica é produzida ao final do processo da fotossíntese

A etapa de fixação do carbono é descrita por Santos e colaboradores (SANTOS et al. 2010) como uma sequência cíclica de reações, denominada ciclo de CalvinBenson, ou ciclo das pentoses, em que resultam duas moléculas de gliceraldeído 3fosfato (3-GP), que tem três átomos de carbono, mencionado como o principal componente orgânico do ciclo. Os autores Pezzi (PEZZI et al., 2010) e Gewandsznajder (GEWANDSZNAJDER et al., 2010) também mencionam a formação do fosfoglicerato, com três carbonos, na etapa que denominam escura ou química. Mendonça (MENDONÇA et al., 2010), também mostra o ciclo de Calvin-Benson, porém, segundo os autores, diz genericamente que nesse ciclo são formadas moléculas de carboidrato $\left(\mathrm{CH}_{2} \mathrm{O}\right)_{n}$ e água. Os autores (SANTOS et al., 2010) afirmam que uma parte do 3-GP, que não continua no ciclo, é utilizada para a formação de compostos orgânicos, particularmente a glicose. De maneira semelhante, outros autores mostram que a partir do fosfoglicerato serão formados açucares, ácidos graxos e aminoácidos, sendo que Pezzi (PEZZI et al., 2010) menciona a glicose e a ribulose e Lopes (LOPES et al., 2010) que os açúcares, o amido e a celulose estão especialmente nas células que ainda estão em crescimento.

Para, Santos (SANTOS et al. (2010), além da glicose, o gliceraldeído 3-fosfato é a base para formação de outras moléculas como amido e sacarose. Mendonça (MENDONÇA et al., 2010) descreve que a molécula $\mathrm{CH}_{2} \mathrm{O}$ formada no ciclo de CalvinBenson sofre polimerização imediata, originando açúcares simples. No entanto, os mesmos autores mencionam que a glicose é o açúcar principal formado e que a partir dela a planta produz os açúcares mais complexos como o amido e a sacarose, referida como o açúcar comum.

Um livro de introdução à botânica utilizado na graduação afirma que os açúcares simples de três carbonos produzidos pelo ciclo de Calvin são utilizados na produção de moléculas mais complexas, como a glicose (NABORS, 2012).

Gewandsznajder (GEWANDSZNAJDER et al., 2010) afirma que parte do aldeído fosfoglicérico produzido é convertida em amido, outra parte é convertida em ácido pirúvico e utilizada na respiração celular, e também pode ser convertida em sacarose. Porém, apesar disso, mostra uma representação da glicose sendo produzida a partir do PGAL (aldeído fosfoglicérico) (Fig. 3). 


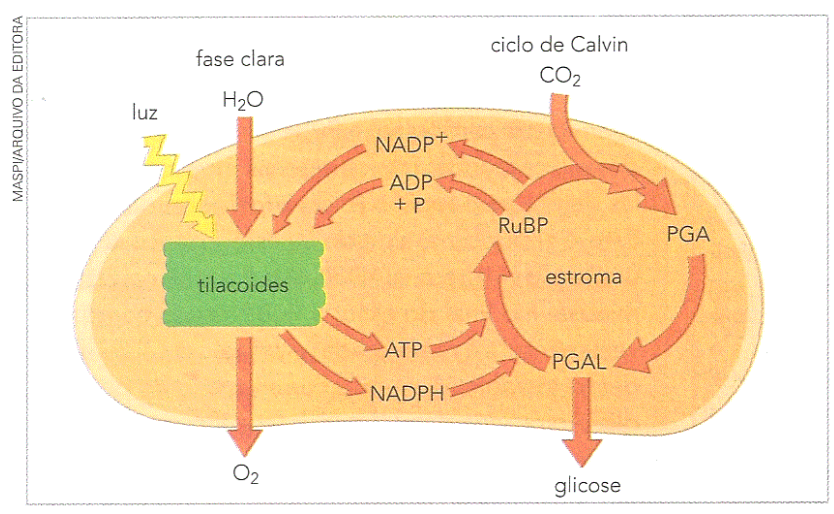

Figura 3 - Resumo geral das etapas da fotossíntese com a produção de glicose (GEWANDSZNAJDER et al., 2010)

Outros autores (SANTOS et al., 2010; MENDONÇA et al., 2010) também realizam essa representação do cloroplasto de maneira semelhante, como figuras mostrando a produção de glicose a partir do ciclo das pentoses (Fig. 4a e 4b).

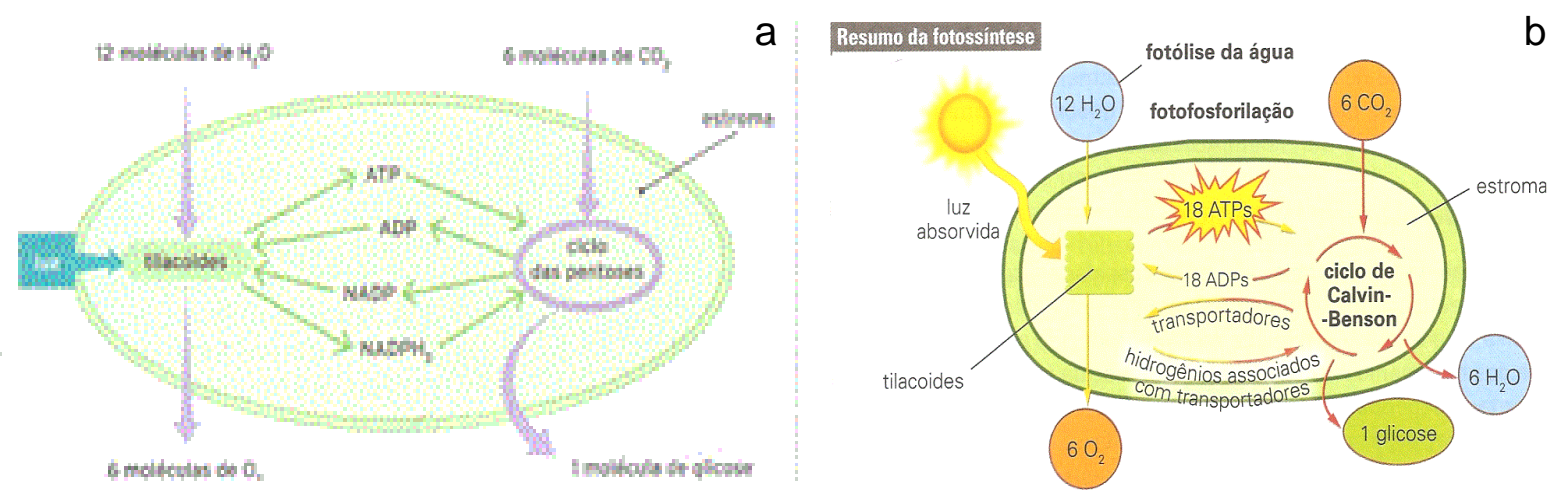

Figura 4 - Esquema do cloroplasto mostrando o ciclo das pentoses com a produção de (a) 1 molécula de glicose e (b) 1 glicose. (SANTOS et al. 2010) e (MENDONÇA et al., 2010), respectivamente

Silva Júnior (SILVA JÚNIOR et al. 2010) e Bizzo (BIZZO, 2011) apresentam um esquema do cloroplasto que mostra a produção de compostos orgânicos $\left(\mathrm{CH}_{2} \mathrm{O}\right)_{n}$ a partir do Ciclo de Calvin, diferentemente dos demais autores (Fig. $5 a$ e $5 b$ ).

Também diferentemente dos demais autores, que sempre mencionam a glicose como produto final da fotossíntese ou um dos produtos, Amabis (AMABIS et al., 2010) diz que as moléculas de gliceradeído-3-fosfato (PGAL), formadas no ciclo Calvin-Benson, podem seguir dois caminhos, transformando-se em amido, no cloroplasto e sacarose, no citosol, considerada pelos 
autores como o principal produto deste processo. Bizzo (BIZZO, 2011) reforça ainda que, embora a glicose seja apresentada tradicionalmente como produto final do processo de fotossíntese, isto decorre apenas de uma simplificação didática do processo. Mais ainda, esse autor diz que o principal produto da fixação do carbono é a sacarose, principal forma de carboidrato transportada nos vegetais, sendo muito solúvel em água. O amido é produzido de forma secundária, com função de reserva, sendo pouco solúvel em água e melhor armazenado.
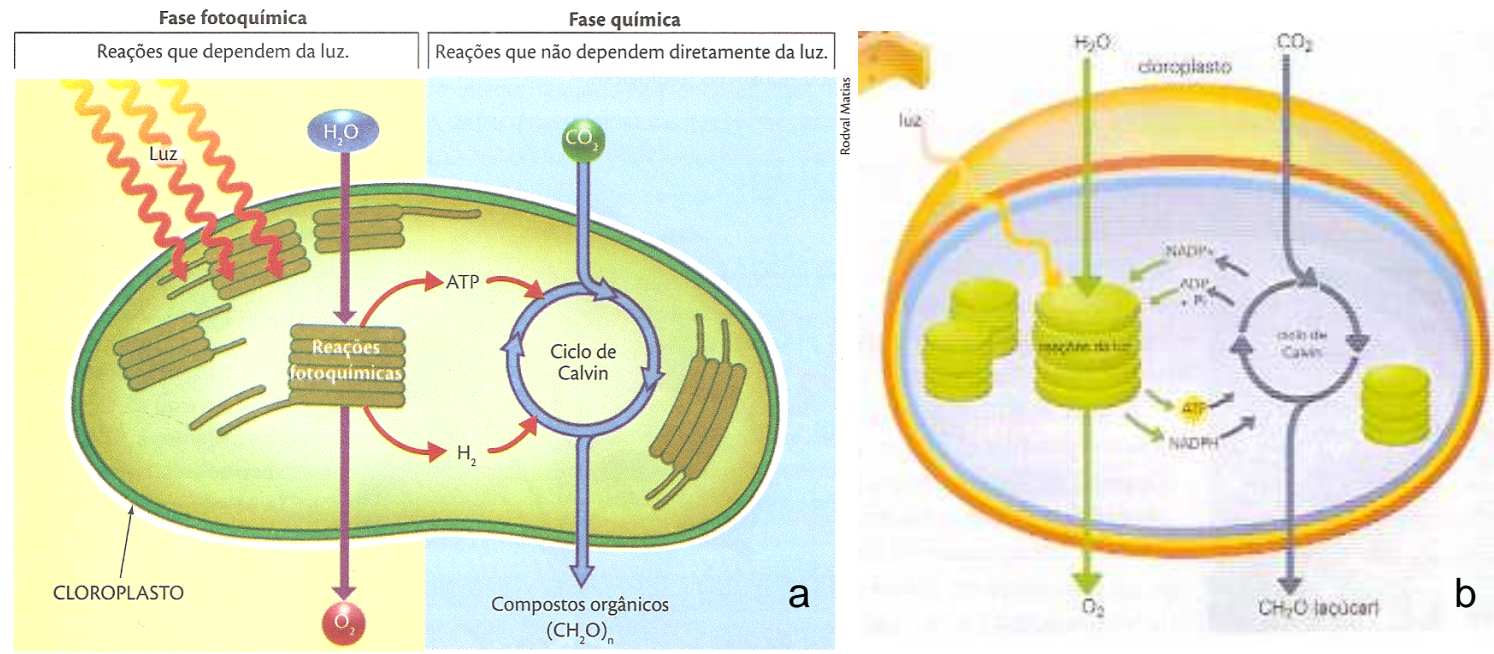

Figura 5 - Esquema do ciclo de Calvin-Benson com a produção de $\left(\mathrm{CH}_{2} \mathrm{O}\right)_{\mathrm{n}}$, representado como (a) compostos orgânicos ou (b) açúcar. (SILVA JúNIOR et al. 2010) e (BIZZO, 2011), respectivamente.

\section{Análise geral de todos os livros avaliados}

De uma maneira geral, a conceituação da fotossíntese pela maioria dos livros ocorre de forma correta, apontando-a como um processo em que há a produção de moléculas orgânicas a partir de moléculas inorgânicas, como a água e o dióxido de carbono, com participação da energia luminosa. A maioria dos livros menciona a glicose como o produto final da reação (CANTO, 2009; SANTANA et al., 2009; PEREIRA et al., 2009; FAVALLI et al., 2010; GEWANDSZNAJDER, 2010; BARROS et al., 2010; SANGARI, 2007; FIGUEIREDO et al., 2009; NABORS, 2012). A glicose é representada como produto do ciclo de Calvin, em algum esquema (AMABIS et al., 2010;
SANTOS et al., 2010; MENDONÇA et al., 2010), ou ainda, aparece como produto final da equação geral da fotossíntese (Reação 6), representada por sua fórmula química $\mathrm{C}_{6} \mathrm{H}_{12} \mathrm{O}_{6}$ (SANTOS et al., 2010; SILVA JÚNIOR et al., 2010; GEWANDSZNAJDER et al., 2010; LOPES et al., 2010; MENDONÇA et al., 2010).
$6 \mathrm{CO}_{2}+6 \mathrm{H}_{2} \mathrm{O} \rightarrow \mathrm{C}_{6} \mathrm{H}_{12} \mathrm{O}_{6}+6 \mathrm{O}_{2}$ (Reação 6)

Taiz (TAIZ et al., 2004) cita as reações da fotossíntese como complexas e considera que pelo menos 50 etapas intermediárias já foram identificadas. As reações do ciclo de 
Calvin, responsáveis pela formação de compostos orgânicos, são denominadas "reações de carboxilação da fotossíntese". O composto orgânico formado neste ciclo é o gliceraldeído 3-fosfato (G3P), uma molécula com função aldeído. Porém, Taiz (TAIZ et al., 2004), Amabis (AMABIS et tal., 2010) e Nabors (NABORS, 2012) consideram-no como um carboidrato. Essa afirmação ocorre provavelmente devido à função energética desta molécula e de sua fórmula química $\mathrm{C}_{3} \mathrm{H}_{6} \mathrm{O}_{3}$, que se enquadra na fórmula básica dos carboidratos $\left(\mathrm{CH}_{2} \mathrm{O}\right)_{n}$. No entanto, $\mathrm{O}$ G3P é um aldeído precursor na formação dos carboidratos mais comuns nos vegetais, a sacarose e o amido, mas não pode ser considerado um açúcar.

Apesar de mencionar a formação de glicose, inclusive citando suas fórmulas químicas na reação geral, Nabors (NABORS, 2012) afirma que moléculas de açúcaresfosfato com três carbonos denominados gliceraldeído-3-fosfato (G3P) são usadas para produzir outros tipos de moléculas de açúcares de seis carbonos, incluindo a glicose e a frutose, que se ligam para formar a sacarose, composto com 12 átomos de carbono. Mais adiante, o mesmo autor menciona, de uma maneira diferente, os destinos metabólicos do G3P formados no ciclo de Calvin. Os destinos metabólicos seriam a conversão de frutose 6-fosfato (F6P) e frutose bifosfato, além da conversão de glicose 6-fosfato (G6P) e glicose 1-fosfato (G1P). A G1P é usada para formar celulose nas paredes celulares e amido para armazenar energia e, a F6P e a G1P produzem sacarose transportada através da planta.

Desta forma, apesar de muitos autores afirmarem que há a formação de glicose, ela ocorre de maneira fosfatada, e é apenas um composto precursor na produção de outros açúcares mais comumente encontrados e usados nos vegetais.

\section{CONSIDERAÇÕES FINAIS}

Esperamos que, com a análise realizada neste artigo, tenhamos contribuído para uma efetiva avaliação de livros didáticos de Ciências e Biologia para o ensino fundamental e médio, que não seja centrada apenas em aspectos visuais, com grande apelo ao público, mas com falhas conceituais, mas que seja, principalmente, um esforço de mudança da qualidade das obras publicadas em nosso país.

Neste artigo, analisamos os livros didáticos utilizados no ensino médio e fundamental, com auxílio de livros de graduação, para corroborar novas propostas para definição da fotossíntese e sua equação. Para os livros de ensino fundamental, se propõe que seja usada a definição mais geral de produção de açúcares como a sacarose e amido a partir de dióxido de carbono e água, com a participação da energia luminosa. Já nos livros de ensino médio, a proposta é que se utilize a equação geral (Reação 5) que apresenta, como produto, a fórmula química geral para os carboidratos $\left(\mathrm{CH}_{2} \mathrm{O}\right)_{n}$. Esta reação, inclusive, foi citada por Calvin em sua pesquisa que ganhou o Nobel em Química (Calvin, 1961). Quando os produtos do ciclo de Calvin forem mencionados, que seja explicado que o G3P é um aldeído precursor de açúcares como a sacarose e amido. Caso haja a necessidade de aprofundar a explicação quanto à formação desses açúcares, que sejam apresentados os subprodutos G1P e F6P nesta citação. Além disso, é importante rever os conceitos e equações nos livros de graduação, sempre procurando esclarecer mais o processo da fotossíntese, ao invés de torná-lo mais confuso citando fatos e compostos que não ocorrem. 


\section{REFERÊNCIAS BIBLIOGRÁFICAS:}

ALVARENGA, J. P. Ciências integradas: $7^{\circ}$ ano. Curitiba, Editora Positiva, 1 ed., v.2, 2008.

AMABIS, J. M. e MARTHO, G. R. Biologia. São Paulo, Moderna, 3 ed., v. 1, 2010.

BARROS, C. e PAULINO, W. R. Ciências. São Paulo, Ática, 4 ed., v. 2, 2010.

BIZZO, N. Novas bases da biologia. São Paulo, Ática, 2 ed., v. 2, 2011.

BIZZO, N. e JORDÃO, M. Ciências BJ. São Paulo, Editora do Brasil, 1 ed., v. 1, 2009.

CALVIN, M. The path of carbon in photosynthesis. Nobel Lecture. Angewandte Chemie International Edition, v.1, n. 2, p. 65-128, 1961.

CANTO, E. L. Ciências naturais: aprendendo com o cotidiano. São Paulo, Moderna, 3 ed., v. 2, 2009.

FAVALLI, L. D. Projeto radix: ciências, $\mathbf{7}^{\circ}$ ano. São Paulo, Scipione, 1 ed., v. 2, 2010.

FIGUEIREDO, M. T. e CONDEIXA, M. C. G. Ciências: Atitude e Conhecimento. São Paulo, FTD, 1. ed., v. 2, 2009.

GEWANDSZNAJDER, F. Ciências. São PauIo, Ática, 4 ed., v. 2, 2010.

LINHARES, S. e GEWANDSZNADJER, F. Biologia Hoje. São Paulo, Ática, 1 ed., v. 1, 2010.

LOPES, S. e ROSSO, S. Bio: volume 1. São Paulo, Saraiva, 1 ed., v. 1, 2010.

MENDONÇA, V. e LAURENCE, J. Biologia: ecologia, origem da vida e biologia celular, embriologia e histologia. São Paulo, Nova Geração, 1 ed., v. 1, 2010.

NABORS, M. W. Introdução à Botânica. São Paulo, Roca, 1 ed., 2012.
PEREIRA, A. M.; SANTANA, M. e WALDHELM, M. Ciências, $7^{\circ}$ ano: volume 2. São Paulo, Editora do Brasil, 1 ed., v. 2, 2009.

PEZZI, A.; GOWDEK, C. O. e MATTOS, N. S. Biologia: citologia, embriologia, histologia. São Paulo, FTD, 1 ed., v.1, 2010.

SANGARI do Brasil, Centro de Pesquisa e Desenvolvimento. Diversidade das Plantas. São Paulo, Sangari Brasil, 10 ed., 2007.

SANTANA, O. A. e FONSECA, A. Ciências naturais, $7^{\circ}$ ano. São Paulo, Saraiva, 3 ed., v. 2, 2009.

SANTOS, F. S.; AGUIAR, J. B. V. e OLIVEIRA, M. M. A. Biologia: ensino médio. São Paulo, Edições SM, 1 ed., v. 1, 2010.

SILVA JÚNIOR, C. e SASSON, S. Biologia: volume 1. São Paulo, Saraiva, 8 ed., v. 1, 2010.

TAIZ, L. e ZEIGER, E. Fisiologia Vegetal. Porto Alegre, Artmed, 3 ed., 2004. 